\title{
Thoracic Cavity
}

National Cancer Institute

\section{Source}

National Cancer Institute. Thoracic Cavity. NCI Thesaurus. Code C12905.

The cavity in the vertebrate body enclosed by the ribs between the diaphragm and the neck and containing the lungs and heart. 